\title{
A temática da gravidez na adolescência numa feira de ciências: Contracepções, responsabilidades e impactos ambientais causados por uma criança
}

\author{
The theme of teenage pregnancy in a science fair: Contraceptions, responsibilities and \\ environmental impacts caused by a child
}

El tema del embarazo adolescente en una feria de ciencias: Anticonceptivos, responsabilidades e impactos ambientales causados por un niño

Talita Fraguas

ORCID: https://orcid.org/0000-0003-2048-456X Universidade Tecnológica Federal do Paraná, Brasil E-mail: tafraguas@hotmail.com Ronualdo Marques

ORCID: https://orcid.org/0000-0001-6681-9914 Universidade Federal do Paraná, Brasil E-mail: ronualdo.marques@gmail.com

Carlos Eduardo Fortes Gonzalez ORCID: https://orcid.org/0000-0003-0180-5153 Universidade Tecnológica Federal do Paraná, Brasil E-mail: cefortes@yahoo.com Claudia Regina Xavier

ORCID: https://orcid.org/0000-0001-6346-648X Universidade Federal do Paraná, Brasil E-mail: cxavier.utfpr@gmail.com

\begin{abstract}
Resumo
Este é um relato de experiência sobre um trabalho realizado em uma Feira de Ciências, sobre Educação Ambiental e sustentabilidade, utilizando a temática da Gravidez na adolescência no Colégio Estadual Deputado Olívio Belich em Curitiba - Paraná. O objetivo foi sensibilizar os estudantes sobre a importância de conhecer e respeitar o próprio corpo, a seriedade da utilização dos métodos contraceptivos, as responsabilidades, o impacto ambiental causado ao meio ambiente, as despesas, e o tempo de decomposição dos produtos utilizados por uma criança nos primeiros anos de vida. Com isso, refletiu-se: como o tema métodos contraceptivos e gravidez pode ser relacionado à Educação Ambiental? No primeiro momento, explanou-se sobre as mudanças psicológicas, físicas e hormonais ocorridas na puberdade, seguindo com a apresentação dos métodos contraceptivos mais comuns e uma roda de conversa sobre a gravidez na adolescência. A partir disso, os estudantes buscaram informações sobre quais itens são utilizados pelos bebês até os três anos de idade, a quantidade, o volume de lixo produzido, o tempo de decomposição, os cuidados que se deve ter com um bebê, o preço dos métodos contraceptivos para a produção de stands na feira de ciências. Constatou-se que os estudantes tiveram participação efetiva nas atividades sobre a temática da gravidez na adolescência sensibilizando a comunidade escolar na feira de ciências sobre a importância de cuidar do próprio corpo, o uso do preservativo para evitar contaminações por doenças, a seriedade dos métodos contraceptivos, e os impactos de uma gravidez não planejada para a própria vida.
\end{abstract}

Palavras-chave: Educação ambiental; Sexualidade; Gravidez na adolescência; Volume de lixo.

\begin{abstract}
This is an experience report about a work done in a Science Fair, about Environmental Education and sustainability, using the teenage pregnancy theme at Colégio Estadual Deputado Olívio Belich in Curitiba - Paraná. The objective was to raise the students' awareness about the importance of knowing and respecting one's own body, the seriousness of using contraceptive methods, the responsibilities, the environmental impact caused to the environment, the expenses, and the decomposition time of the products used by a child in the first years of life. Thus, we reflected: how can the theme contraceptive methods and pregnancy be related to Environmental Education? In the first moment, the psychological, physical, and hormonal changes that occur during puberty were explained, followed by the presentation of the most common contraceptive methods and a conversation about pregnancy in adolescence. After that, the students searched for information about which items are used by babies until they are three years old, the amount and volume of waste produced, the decomposition time, the care one should have with a baby, and the price of contraceptive methods to produce stands at the science fair. It was verified that the students had an effective
\end{abstract}


participation in the activities about the theme of pregnancy in adolescence, sensitizing the school community in the science fair about the importance of taking care of one's own body, the use of condoms to avoid contamination by diseases, the seriousness of contraceptive methods, and the impacts of an unplanned pregnancy on one's own life.

Keywords: Environmental education; Sexuality; Teenage pregnancy; Garbage volume.

\section{Resumen}

Este es un informe de experiencia sobre un trabajo realizado en una Feria de Ciencias, sobre Educación Ambiental y sostenibilidad, utilizando el tema del embarazo en la adolescencia en el Colégio Estadual Deputado Olívio Belich en Curitiba - Paraná. El objetivo era concienciar a los alumnos sobre la importancia de conocer y respetar su propio cuerpo, la seriedad de utilizar métodos anticonceptivos, las responsabilidades, el impacto ambiental causado al entorno, los gastos y el tiempo de descomposición de los productos utilizados por un niño en los primeros años de vida. Con ello, se reflexionó: ¿cómo se puede relacionar el tema de los métodos anticonceptivos y el embarazo con la Educación Ambiental? En un primer momento, se explicaron los cambios psicológicos, físicos y hormonales que se producen en la pubertad, seguido de la presentación de los métodos anticonceptivos más comunes y una ronda de conversación sobre el embarazo en la adolescencia. A partir de ahí, los alumnos buscaron información sobre los artículos que utilizan los bebés hasta los tres años, la cantidad, el volumen de residuos producidos, el tiempo de descomposición, los cuidados que se deben tener con un bebé, el precio de los métodos anticonceptivos para la producción de stands en la feria de ciencias. Se comprobó que los alumnos tuvieron una participación efectiva en las actividades sobre el tema del embarazo adolescente, sensibilizando a la comunidad escolar en la feria de ciencias sobre la importancia del cuidado del propio cuerpo, el uso del preservativo para evitar la contaminación por enfermedades, la seriedad de los métodos anticonceptivos y los impactos de un embarazo no planificado en la vida.

Palabras clave: Educación ambiental; Sexualidad; Embarazo adolescente; Volumen de basura.

\section{Introdução}

É imprescindível tratar das questões relacionadas à sexualidade no Ensino de Ciências, principalmente no que tange ao conhecimento do próprio corpo, dos métodos contraceptivos, das doenças sexualmente transmissíveis e da gravidez na adolescência. Muitos estudantes ainda não têm abertura ou diálogo para tratar destas questões em suas casas, se sentem desconfortáveis, em contraponto, os pais em busca da sobrevivência na sociedade, trabalham o dia todo, e os filhos acabam desta forma, buscando estas informações de forma incorreta. Por isso, é de extrema importância abordar esses temas em sala de aula. Para que assim, os estudantes aprendam acerca do próprio corpo, tirem suas dúvidas sobre os diversos tipos de métodos contraceptivos, sejam orientados sempre a procurar auxílio de um médico ginecologista na busca de um método ideal para o seu corpo e aprendam sobre estes temas de forma científica, segura e adequada.

A sexualidade é um aspecto central do ser humano ao longo da vida e inclui o sexo, género, identidades e papéis, orientação sexual, erotismo, prazer, intimidade e reprodução. A sexualidade é experienciada e expressa através de pensamentos, fantasias, desejos, crenças, atitudes, valores, comportamentos, práticas, papéis e relações. Embora a sexualidade possa incluir todas estas dimensões, nem sempre elas são todas experienciadas ou expressas. A sexualidade é influenciada pela interação de fatores biológicos, psicológicos, sociais, económicos, políticos, culturais, éticos, legais, históricos, religiosos e espirituais (Oms, 2006, p. 5).

Desta forma, assimila-se que a sexualidade trata do comportamento social, de como a pessoa trata o próprio corpo e não somente do ato sexual em si. Percebe-se que conhecendo o próprio corpo a pessoa aprende a respeitá-lo e ter zelo pela própria saúde em prol do seu bem-estar. Quando se trata da sexualidade, procura-se também tratar da importância de ir ao médico em busca de um método anticoncepcional ideal para o corpo com a finalidade de evitar uma gravidez indesejada no período da adolescência e a importância da utilização do preservativo para evitar a contaminação por uma doença sexualmente transmissível.

O que se constata é que apesar de ter muitas informações acerca dos métodos anticoncepcionais no mundo a cada 1 mil meninas entre 15 e 19 anos nascem 46 crianças, já na América Latina e Caribe a cada 1 mil meninas nesta idade nascem 66 bebês, enquanto que no Brasil nascem 68 bebês a cada 1 mil adolescentes (Onubr, 2018). Constata-se, que a taxa de adolescentes grávidas no Brasil é muito acima da média mundial, e essa gravidez no período desenvolvimento pode ser 
perigoso tanto para a mãe quanto para o bebê. Outro fator que influencia na gravidez na adolescência é o social. Com os dados da ONU verifica-se de fato que as adolescentes não buscam informação acerca dos métodos contraceptivos no nosso país, ou colhem estas informações em fontes não seguras, acabam engravidando antes do tempo desejado, e isso pode trazer sérios riscos à saúde da mãe e do bebê.

Para Drauzio Varella, a gravidez no período da adolescência traz mais riscos à saúde, pois, o corpo da adolescente está em transformação, algumas delas não apresentam peso e altura ideal para gerar uma criança, o pré-natal em algumas vezes não é feito, além de consumirem bebidas alcóolicas e fumarem durante o período da gravidez, podendo causar a eclampsia e pré-eclâmpsia, os bebês podem nascer prematuros com baixo peso, há riscos também de deficiência nutricional e anemia (Conte, 2019). Já uma adulta busca fazer os exames regularmente, cuidar da alimentação, não beber e não fumar para não prejudicar a gestação.

O lixo sempre foi e é motivo de preocupação nas questões relacionadas ao meio ambiente e à saúde, pois, contamina a água, o solo e o ar influenciando em todos os ecossistemas da Biosfera. A correria do cotidiano, a vida atribulada do casal moderno, buscando sempre uma maior renda à família e a inovação da tecnologia fez com que alguns hábitos de vida fossem modificados, influenciando diretamente na quantidade de lixo produzido, sendo assim, o volume destes resíduos foi aumentado de forma significativa, por exemplo, segundo o portal G1 - Globo (2019), nos últimos 30 anos, a geração de resíduos nas cidades aumentou três vezes mais do que a população urbana. O portal G1 - globo (2019) também pontua que produzimos 1,4 bilhões de toneladas por ano, o que significa que cada um dos habitantes do planeta é responsável por produzir mais de um quilo de lixo por dia. Isso se constata entre os materiais utilizados em bebês como cadeirinhas para carros e babás eletrônicas por exemplo.

As fraldas utilizadas na antiguidade eram de pano, ou seja, laváveis, possíveis de reutilização várias vezes, sem a necessidade de descartá-las constantemente no meio ambiente, as mamadeiras eram de vidro e assim como as roupas algumas vezes eram passadas para vários irmãos na família. Na atualidade, as fraldas de pano foram substituídas por descartáveis e estas levam em média 600 anos para se decompor na natureza (Portal São Francisco, 2015). Como resultado disso se verificam os aterros sanitários repletos de fraldas usadas e mamadeiras de plástico descartadas, sendo que estas podem ser separadas para serem recicladas. Inclusive a roupa tem sido desenhada para durar menos, também se encontram descartadas ou reutilizadas para limpeza. Segundo o portal Ecycle (2019) as roupas são feitas de poliéster justamente para durar menos, e com isso os aterros sanitários sofrem as consequências, o portal aponta que a doação das roupas seria uma excelente opção para evitar o acúmulo deste produto nos aterros sanitários (Portal Ecycle, 2019).

Segundo o portal da Pampers (2019), um das maiores produtores de fraldas do mundo, a criança nos seus primeiros vinte dias utiliza em média 8 fraldas por dia; de vinte a quarenta dias utiliza em média 7 fraldas por dia; do segundo ao quarto mês utiliza 6 fraldas por dia; no quinto mês ao vigésimo mês utiliza em média 5 fraldas por dia; e do vigésimo primeiro até os três anos de idade, ou seja, até mais ou menos o trigésimo sexto mês utiliza 4 fraldas diariamente. Fazendo as contas com estes dados estatísticos constatou-se que um bebê na sua infância utiliza em média acima de 5000 fraldas, estas não serão reaproveitas, simplesmente serão descartadas aumentando cada vez mais a quantidade de lixo nos aterros sanitários. Temos de lembrar que as fraldas contêm urina e fezes que são altamente contaminantes, podem também conter vermes e até mesmo causar doenças na população. Segundo o Portal São Francisco (2015), uma fralda descartável comum leva de 450 a 600 anos (Portal São Francisco, 2015) para se decompor, com isso constata-te que sua decomposição é extremamente lenta. Além disso, ela apresenta diversos componentes químicos.

A composição de uma fralda descartável pode ser de aproximadamente $43 \%$ de polpa de celulose (celulose fluff), $27 \%$ de polímero superabsorvente (PSA), 10\% de polipropileno (PP), 13\% de polietileno (PE), e 7\% de fitas, elásticos e adesivos. Tendo para isso, em sua fabricação, a utilização de recursos como árvores, petróleo, água e produtos químicos. Na configuração da fralda, o polipropileno compõe a camada que entra em contato direto com o bebê, e sua 
função é facilitar o escoamento do líquido para a camada absorvente. Os polímeros superabsorventes possuem grande afinidade pela água; estes, junto com a polpa de celulose, formam a manta de gel superabsorvente, que é colocada no recheio da fralda com a finalidade de absorver os líquidos. O revestimento do produto é composto por polietileno, um polímero hidrofóbico (tem aversão a água) que é colocado na parte exterior e nas laterais, a fim de evitar o vazamento de líquido para fora da fralda (Equipe ecycle, 2019).

Com todos os componentes químicos presentes nas fraldas, constata-se que esses são prejudiciais à natureza, já que na sua produção tem-se a extração da matéria na natureza para sua fabricação, após ser fabricada por máquinas, estas são transportadas para as farmácias, mercados através de caminhões, poluindo o meio ambiente, da prateleira ela será comprada e depois de utilizada será descartada, com um destino final que é o lixão ou aterro sanitário.

Segundo Reghin (2017), o Brasil é o terceiro maior consumidor de fraldas descartáveis no mundo, ele ainda complementa só perdemos para os Estados Unidos e para a China. O autor pontua que uma criança gera $400 \mathrm{~kg}$ de lixo em um ano.

A importância da amamentação é evidente para a saúde do bebê, porém, algumas mães por terem que trabalhar, ou pela falta de tempo para essa prática devido aos compromissos diários, substituem o leite materno pelo leite em pó especial para bebês, estes leites são embalados em latas de alumínio e duram em média uma semana, elas além de aumentarem o volume do lixo, se não forem destinadas à reciclagem, segundo o Portal São Francisco (2015) demoram mais de duzentos anos para se decompor, além disso, esse leite tem um custo alto para as famílias. Outros motivos que as mães apresentam para não amamentarem, segundo Delboni (2017), são a dor - devido ao bico rachado, ou o seio estar muito cheio de leite; pouco leite que ao amamentar sua produção será estimulada; ter o bico invertido - voltado para dentro; falta de apoio e críticas - os familiares se intrometem, porém, não ajudam nos cuidados ao bebê; falta de informação e preparo - nos cursos o conteúdo é superficial.

A Educação Ambiental e a sustentabilidade podem melhorar a qualidade de vida das pessoas, atuando na saúde e no meio ambiente, e se estamos tratando de crianças devemos pensar qual futuro deixaremos a nossos descendentes sendo assim, a Lei no 9.795 define Educação Ambiental como:

Os processos por meio dos quais o indivíduo e a coletividade constroem valores sociais, conhecimentos, habilidades, atitudes e competências voltadas para a conservação do meio ambiente, bem de uso comum do povo, essencial à sadia qualidade de vida e sua sustentabilidade (Brasil, 1999, Art. $1^{\circ}$ ).

O Programa Nacional de Educação Ambiental prevê que a sustentabilidade e a Educação Ambiental devem buscar sempre melhorar a qualidade de vida da população. (Brasil, 2005). No que se trata da sexualidade, está também busca melhorar a qualidade de vida do indivíduo, pois, conhecendo o próprio corpo, aprende-se a respeitá-lo mais. É relevante que se passe da discussão à prática que favoreça efetivamente a população no tocante as questões da Educação Ambiental e da sexualidade.

Marques, Gonzalez e Xavier (2017) corroboram ao afirmar que a Educação Ambiental pode proporcionar "a transposição de mudanças comportamentais e aquisição de novos valores e conceitos convergentes às necessidades do mundo atual, com as inter-relações e as interdependências que se estabelecem entre os ambientes naturais, socioculturais e as outras dimensões; econômica, psicológica, etc" (Marques, Gonzalez \& Xavier, 2017, p. 2).

Boff (2015) define a sustentabilidade como o conjunto de processos e ações que objetivam manter a continuidade do Planeta, protegendo assim todos os ecossistemas e possibilitando, assim, a continuidade da vida na Terra, por meio da constante evolução da humanidade.

Assim como Boff (2015), Leff (2001) corrobora com suas ideias e aponta que "a sustentabilidade ecológica aparece assim como critério normativo para a reconstrução da ordem econômica, como uma condição para a sobrevivência humana e um suporte para chegar a um desenvolvimento duradouro, questionando as próprias bases da produção" (Leff, 2001, p. 15). O 
autor acrescenta que "o conceito de sustentabilidade surge, portanto, do reconhecimento da função de suporte da natureza, condição e potencial do processo de produção" (Leff, 2001, p. 15).

O discurso da 'sustentabilidade' leva, portanto, a lutar por um crescimento sustentado, sem uma justificação rigorosa da capacidade do sistema econômico de internalizar as condições ecológicas e sociais (de sustentabilidade, equidade, justiça e democracia) deste processo (Leff, 2001, p. 19-20).

Em um colégio de Curitiba, para apresentação na Feira de Ciências sobre Educação Ambiental e Sustentabilidade, com aproximadamente trinta alunos do oitavo ano, foi feita uma pesquisa acerca de quanto um recém-nascido gasta monetariamente com materiais de higiene, vestimentas, roupas de cama, itens de transporte, alimentação e medicamento; os cuidados que devemos ter com eles; a quantidade de lixo que eles produzem até o terceiro ano de vida e o preço dos métodos contraceptivos, com o intuito de demonstrar valores sociais, culturais, ambientais e econômicos, ou seja, que uma criança gera muitas despesas, cuidados e responsabilidades a um adulto, imagina para os adolescentes, atrelando assim a Educação Ambiental com a sexualidade.

O objetivo dessa pesquisa foi demonstrar aos estudantes a importância de conhecer e respeitar o próprio corpo em prol de uma melhoria da qualidade de vida, a o compromisso pessoal de utilizar os métodos contraceptivos, pois, estes evitam uma gravidez indesejada e a camisinha evita a contaminação por doenças sexualmente transmissíveis, as responsabilidades de se ter um filho, já que um bebê muda completamente a rotina da pessoa, com a amamentação, acorda no período noturno e exige muitos cuidados, o impacto ambiental causado ao meio ambiente, uma vez que os bebês utilizam fraldas descartáveis, mamadeiras, chupetas, roupas e outros produtos, as despesas, e o tempo de decomposição dos produtos utilizados pelos bebês, principalmente as fraldas que apresentam uma decomposição muito lenta.

\section{Metodologia}

Este é um relato de experiência sobre um trabalho realizado em uma Feira de Ciências, sobre Educação Ambiental e sustentabilidade, no segundo semestre de 2018, no município de Curitiba - Paraná, em conjunto com aproximadamente trinta estudantes do oitavo ano, professores, funcionários, direção e equipe pedagógica do Colégio Estadual Deputado Olívio Belich.

A pesquisa se dá na perspectiva da Pesquisa Participante de natureza qualitativa. Borda (1988) estabeleceu alguns princípios metodológicos da Pesquisa Participante começando com Autenticidade e Compromisso. Autenticidade no sentido de produzir um saber que parte do saber do seu sujeito-objeto, constituído na prática comunitária, demonstrando com transparência e honestidade um compromisso com o saber a ser construído contribuindo com os princípios específicos da Ciência sem a necessidade do disfarce como sujeito de origem da área delimitada para o estudo.

Por isso, ressalta-se que a pesquisa qualitativa refere-se a avaliações e interpretações críticas e qualitativas (Higgs \& Cherry, 2009) da realidade. Ludke e André (2015) asseveram que o papel do pesquisador na abordagem qualitativa é de estar atento à multiplicidade de dimensões de uma determinada situação ou problema e após a análise dos dados, ele lança possibilidades de explicação da realidade, tentando encontrar princípios subjacentes ao fenômeno estudado e situar as suas descobertas num contexto mais amplo; trata-se de um esforço de construção ou estruturação de um quadro teórico, dentro do qual o fenômeno possa ser interpretado e compreendido.

Marques e Xavier (2018) afirmam que a Pesquisa Participante começa por reconhecer que há uma relação estreita entre ciência social e intervenção na realidade com vistas a promover a superação das dificuldades de um determinado grupo social. Isso significa dizer que a Ciência não é o fim em si mesma, mas um instrumento de questionamento sistemático para a construção do conhecimento do cotidiano e do destino humano (Brandão, 2006).

Por ser crítica-dialética, a Pesquisa Participante busca envolver aquele que pesquisa e aquele que é pesquisado no estudo do problema a ser superado, conhecendo sua causa e construindo coletivamente as possíveis soluções. Para a Pesquisa 
Participante, os saberes dos indivíduos construídos no cotidiano da vida comunitária são partes importantes no processo de construção do conhecimento (Brandão, 2006).

Em um primeiro momento, explanou-se todas as mudanças que ocorrem no organismo durante a puberdade no corpo masculino e feminino, os cuidados pessoais e a higiene que devemos ter com o nosso organismo para evitar a contaminação por doenças; o sistema reprodutor masculino e feminino; os gametas feminino e masculino; os métodos contraceptivos naturais (tabelinha, coito interrompido, abstinência, muco cervical) deixando bem claro que eram os métodos que existiam no século passado, antes da invenção da pílula anticoncepcional e que hoje em dia existem método bem mais eficazes; os métodos contraceptivo de barreira (camisinha feminina e masculina) únicos métodos que além de evitar uma gravidez indesejada também evitam a contaminação por doenças sexualmente transmissíveis; os métodos contraceptivos hormonais e (pílula, implante, injeção, adesivo e anel vaginal); os métodos contraceptivos cirúrgicos (vasectomia, histerectomia, laqueadura); comentou-se da invenção da pílula anticoncepcional, do motivo pelo qual as pessoas mais idosas tinham uma quantidade grande de filhos e as doenças sexualmente transmissíveis e seus sintomas, tratamento e como evita-las. Foram explanados os problemas referentes à adolescência, pois, nesta fase há um conflito físico, psicológico e social, e as responsabilidades que virão a partir da vida adulta. Na sequência, os estudantes fizeram uma comparação com os aspectos positivos de uma gestação na idade adulta e os aspectos negativos de uma gestação no período da adolescência, fez-se um apontamento das opiniões, pontuaram-se os problemas que uma gravidez na adolescência pode causar na mãe e no bebê e as responsabilidades acerca de uma criança.

Esclareceram-se os conceitos e a importância da sustentabilidade, bem como os conceitos e a importância de tratar Educação Ambiental nas aulas, não somente para o meio ambiente, mas também para a saúde, já que a Educação Ambiental tem uma abordagem muito ampla, e a Feira de Ciências era sobre Educação Ambiental e sustentabilidade. Após a explanação destes conteúdos, promoveu-se uma roda conversa sobre o que poderia ser abordado na Feira de Ciências, pois, havia a necessidade de relacionar a temática Sustentabilidade e Educação Ambiental com os conteúdos da disciplina de Ciências. Segundo Marques et al., (2017 apud Creswell, 2010) as rodas de conversa como metodologia deve ser utilizada para,

verificar os conhecimentos prévios ou os aprendidos na construção da linguagem cientifica, confrontando diferentes opiniões e novos posicionamentos, a partir das aulas teóricas e práticas estimulando-os, assim, à criatividade e ao "saber ouvir", dando oportunidade aos colegas de se expressarem suas opiniões, dúvidas e anseios. A roda de conversa, como instrumento de trabalho, não foi escolhida sem antes nos depararmos com a necessidade de propiciar à nossa pesquisa um caráter de cientificidade, o que implica caracterizá-la como de natureza qualitativa e determinar sua posição como abordagem legítima da busca do conhecimento científico, posto que esse tipo de pesquisa "[...] é um meio para explorar e para entender o significado que os indivíduos ou os grupos atribuem a um problema social ou humano" (Marques et al., 2017, p. 5).

No oitavo ano geralmente o tema central é o corpo humano. No momento, estávamos trabalhando sistema reprodutor masculino e feminino, as mudanças que ocorrem no corpo na puberdade, métodos contraceptivos, gravidez na adolescência e doenças sexualmente transmissíveis. E os estudantes tiveram a ideia de tratar sobre a quantidade de lixo produzida pelos bebês e a evolução da tecnologia, destacaram também que na idade de seus pais, e seus avós era muito mais fácil cuidar de um filho, pois, na época não tinha tanta influência da mídia para instigar ao consumo de produtos, assim a criança se satisfazia com o que ganhava de seus pais. Com três temas definidos, houve um consenso pelo estudo de quantidade de lixo produzida pelos bebês e a apresentação desse estudo na Feira de Ciências sobre Educação Ambiental e Sustentabilidade. Como mediadores acatou-se a decisão dos estudantes e foi sugerido que eles colocassem nos trabalhos as despesas, a responsabilidade de um bebê e o custo da prevenção para evitar este bebê.

No segundo momento, a sala foi dividida em equipes com quatro, cinco ou seis alunos, sendo definido o que cada equipe faria, com isso, começaram as buscas incessantes em prol de todos os itens utilizados pelos bebês (fraldas, lenços 
umedecidos, pomada para assadura, leite em pó, roupas, cobertas, travesseiro, manta, protetor de berço, remédios, shampoo, sabonete, óleo, comida, carrinho, cadeirinha de refeição, cadeirinha para o carro...) em questão de quantidade e o valor unitário. Foram feitos todos os cálculos para adicionar uma tabela com as despesas no cartaz que seria apresentado na feira. Também foram adicionados os cuidados que os bebês exigem, a quantidade de lixo que produzem (orgânico e reciclável), o tempo de decomposição e a média de preços dos métodos contraceptivos mais comuns na adolescência que são a pílula e a camisinha.

Duas equipes - equipe A e B, se responsabilizaram para trazer as embalagens dos produtos infantis que podem ser recicladas, como embalagem de fralda, lata de leite, caixa de remédio, caixa de pomada antialérgica, potinho de sopa pronta, vidro de shampoo, embalagem de lenços umedecidos, inclusive dois alunos para complementar o trabalho trouxeram algumas roupinhas para que todos tivessem uma noção do volume de lixo produzido por um recém-nascido. Outras equipes - equipe C e $\mathrm{D}$, se responsabilizaram em fazer uma maquete dentro de uma caixa de sapato com os itens utilizados pelos bebês e acabaram realizando a cópia perfeita de um quarto infantil com alguns materiais reciclados, pois, a Educação Ambiental e sustentabilidade era o tema da feira.

Um dos estudantes da outra equipe - equipe E, se encarregou de baixar na internet um choro de bebê para demonstrar que o choro dos bebês, dificultam o sono das pessoas, e acordam várias vezes no período noturno para mamar.

Com todos os dados em mãos, todas as equipes ajudaram na elaboração de um cartaz em papel bobina também conhecido como papel kraft que é de origem reciclável, com aproximadamente 4,5 metros de largura, com uma tabela central a qual constavam os itens utilizados pelos bebês até os três anos de idade, o valor unitário de cada item, a quantidade a ser utilizada nos três anos, a despesa aproximada total, estimativas sobre a quantidade de lixo produzida, o tempo de decomposição destes itens. Na lateral direita, havia as informações e os valor dos métodos contraceptivos, no lado esquerdo continham as responsabilidades, as mudanças que ocorrem na vida da pessoa quando se tem um filho, e o custo total de um bebê até os três anos de idade, fazendo uma comparação de valores entre os métodos contraceptivos e o custo de um filho.

As equipes $\mathrm{A}$ e E se encarregaram de arrumar os produtos na mesa, onde, foram colocadas fraldas descartáveis sem uso embaladas em saco plástico transparente para que estas não se contaminassem, embalagem de leite, embalagem de fralda descartável, fralda, mamadeira, chupeta, lenço umedecido, com a finalidade de demonstrar que estes ocupam muito espaço no meio ambiente.

As equipes $\mathrm{C}$ e $\mathrm{D}$, em paralelo, produziram uma maquete dentro de uma caixa de sapato, uma cópia perfeita de um quarto de bebê - com cadeira de amamentação, berço, guarda-roupas, cômoda, bichinhos de pelúcia - utilizando palitos de sorvetes, camisetas velhas, garrafa pet, massa de modelar, restos de lã e espuma e para fixar esta maquete utilizaram cola quente, agulha e fio de costura. A maquete foi feita para demonstrar que um bebê inspira cuidados e ocupa espaço na casa.

A equipe B se responsabilizou em fazer todos os cálculos que foram contemplados no cartaz, assim como a divisão do cartaz foi de responsabilidade deles.

Como estava envolvendo escrita, saúde, valores monetários, e maquetes, os estudantes realizaram estas atividades nas aulas de Ciências, Matemática, Português, Educação Física, e Arte, tornando assim a atividade interdisciplinar, e sendo importante ao olhar de todas as disciplinas, não somente em Ciências.

Os Parâmetros Curriculares Nacionais - PCNs - enfatizam que "a interdisciplinaridade supõe um eixo integrador, que pode ser o objeto de conhecimento, um projeto de investigação, um plano de intervenção." Os PCNs enfatizam também que a interdisciplinaridade "deve partir da necessidade sentida pelas escolas, professores e alunos de explicar, compreender, intervir, compreensão, mudar, prever, algo que desafia uma disciplina isolada e atrai a atenção de mais de um olhar, talvez vários".

No último momento, o trabalho foi apresentado por todos os estudantes de todas as equipes, na feira de ciências, em forma de revezamento, pois cada apresentação era feita por dois estudantes e durava em média 8 minutos. Dessa forma 
demonstrou-se a todos os alunos e professores do período vespertino da escola o custo, as responsabilidades e as mudanças que ocorrem na vida a partir do nascimento de uma criança. Contabilizando, aproximadamente 300 pessoas visitaram e assistiram a apresentação, dos estudantes, cada turma tinha um horário específico para a visitação na feira. Como os estudantes revezaram nas apresentações, enquanto alguns alunos da sala apresentavam, outros estudantes puderam visitar as outras turmas, observar brinquedos recicláveis, maquetes e tudo o que a feira oferecia.

O cartaz ficou exposto alguns dias no mural da escola e depois foi destinado ao lixo reciclável. A maquete ficou com uma das alunas que a produziram, pois, a mãe da estudante disse que era para ela todo dia olhar a maquete e pensar nas consequências. As embalagens utilizadas para mostrar o volume produzido de lixo foram destinadas segundo a segregação de resíduo como: papel, plástico ou metal, uma vez que não tinha vidro, nem material orgânico na apresentação. As fraldas descartáveis que estavam embaladas voltaram para serem utilizadas, pois, estavam protegidas. A sala foi limpa e organizada pelos próprios estudantes, conforme as orientações estabelecidas pelo colégio.

\section{Resultados e Discussão}

Os estudantes no momento da apresentação ficaram um pouco nervosos e ansiosos, mas o nervosismo e a ansiedade foram desaparecendo à medida que apresentavam. Pôde-se perceber claramente o empenho dos alunos acerca do material produzido. A maioria participou efetivamente dos trabalhos realizados na Feira de Ciências. Com isso, houve a produção de um cartaz de papel bobina com um tamanho grande, ou seja, quase cinco metros de comprimento; a explicação do cartaz que se tornou uma mini palestra; uma maquete em tamanho reduzido sobre os produtos utilizados pelos bebês; e uma mesa repleta de embalagens de produtos que os bebês utilizam no seu cotidiano, com o tempo de decomposição de cada item, estes dados, e o volume que o lixo exposto na mesa, fez com que muitos estudantes que vinham de outras turmas visitar a exposição ficassem chocados com os dados.

Constata-se que a sustentabilidade nas ideias dos autores prevê o crescimento, e o desenvolvimento da humanidade, porém, respeitando condições ecológicas e sociais, para garantir a sobrevivência das gerações futuras. Ainda em seu livro Leff (2001) acredita que "o princípio da sustentabilidade surge como uma resposta à fratura da razão modernizadora e como uma condição para construir uma nova racionalidade produtiva, fundada no potencial ecológico e em novos sentidos de civilização a partir da diversidade cultural do gênero humano" (Leff, 2001, p. 31).

$\mathrm{Na}$ apresentação que os estudantes faziam aos seus colegas de outras turmas, era muito comum eles falarem: "se você não tem nem dinheiro para comprar uma coxinha sem pedir para mãe, imagina para ter um filho, portanto, se for ter relação utilize preservativos"; "se você não tem dinheiro nem para comprar absorvente ou lâmina de barbear, imagina para ter um filho". Outra frase que eles citaram muito foi: "quando se tem um filho você não vai dormir, comer, descansar como faz agora, filhos trazem muita responsabilidade e despesas, por isso é muito importante fazer um planejamento e só ter na hora planejada pelo casal está aqui no cartaz". Além de: "vai no posto de saúde, procure um médico para obter todas as informações que você precisa, não fique na dúvida", e "no posto de saúde tem injeção, pílula, pílula do dia seguinte de graça, mas se forem ter relação, não esqueçam de usar a camisinha porque é a única que evita a contaminação por doenças sexualmente transmissíveis".

Os estudantes durante a apresentação também explicaram que o volume do lixo por um bebê é grande, pois uma criança utiliza aproximadamente 5000 fraldas na infância, fizeram os cálculos da quantidade de lixo produzido por uma pessoa até os 70 anos de idade e concluíram que cada indivíduo produz aproximadamente 25.500 toneladas de lixo, sendo assim até os 5 anos de idade estas crianças produzem em média 2 toneladas de lixo, com estes dados, e com essa quantidade expressiva de lixo é dever dos pais se responsabilizar em separar o lixo utilizado pelo bebê para que este lixo seja descartado adequadamente. 
Também explicitaram o problema das fraldas descartáveis que estas por terem fezes e urina contaminam o meio ambiente e podem até ter vermes.

Um dos estudantes relatou que tem um irmão mais novo, por isso, sabe que os bebês choram muito, fazem muita sujeira e exigem muita responsabilidade dos pais, também notou um pequeno aumento na conta de água, já que a mãe lava roupas bem mais com a chegada do irmão, relatou até mesmo que depois que o irmão nasceu perdeu a atenção dos pais, que o tempo que os pais tinham pra ele agora fica somente no irmão.

Ao se trabalhar essas questões com alunos dessa faixa etária notamos o quanto ficam interessados em debater o assunto, porque diz respeito diretamente a eles. De certo, por mais que não tenham responsabilidade sobre o próprio futuro, no que tange a gravidez na adolescência ou mesmo o perigo de adquirirem doenças, tornam-se atentos e cuidadosos, levando a sério o que se vê e se vive cotidianamente. Assim, é comum em temas como esses chamar a atenção dos estudantes para terem responsabilidade sobre seus corpos e seus respectivos futuros. Ao se pensar em perspectiva de vida e de futuro, é indispensável também se pensar na maneira como se deve levar a sério a vida especialmente nessa idade.

\section{Considerações Finais}

O empenho nesse trabalho foi visível. Os visitantes e professores prestaram atenção em todas as informações dadas. Foi gratificante perceber a participação efetiva de todos os adolescentes da sala, os estudantes ficaram muito satisfeitos e entusiasmados com os próprios trabalhos e ouviram muitos elogios de professores, colegas de outras turmas, funcionários e da direção que visitaram a apresentação.

Nota-se aparentemente que os estudantes do oitavo ano perceberam a importância de conhecer e zelar pelo o próprio corpo em prol de uma melhoria na qualidade de sua própria vida. Por isso, quiseram participar da discussão não apenas como sujeitos passivos, mas agindo como se eles próprios protagonizassem a temática em discussão. O que fica claro é que quando o assunto é de interesse deles eles o tomam com muita seriedade, e participam ativamente das discussões.

Os estudantes também perceberam que estão passando por mudanças físicas, psicológicas e hormonais, que esta fase é bem complicada e que as atitudes deles no momento irão influenciar diretamente no futuro deles mesmos.

Os adolescentes lembraram da importância de buscar um médico em busca de um método contraceptivo ideal para o próprio corpo, já que um organismo reage de forma diferente do outro em relação à medicamentos, e relataram que o uso do preservativo é essencial para evitar a contaminação por doenças sexualmente transmissíveis e uma gravidez indesejada. Os estudantes assimilaram que uma gravidez na adolescência pode trazer riscos à saúde da mãe e do bebê, pois, percebem que o corpo deles está em transformação.

Os adolescentes assimilaram que uma criança exige muita responsabilidade, e tem um alto custo para os pais devido as suas necessidades, pois, estes crescem muito rápido e perdem a roupa constantemente, são dependentes e necessitam muito zelo. Eles notaram que pelo bebê regurgitar algumas vezes, muitas mudas de roupas são trocadas, aumentando assim o consumo de água e por consequência a conta de água fica mais custosa.

Se tomando de exemplos apontaram que quanto mais cresce devido a influência da mídia mais pedem os produtos aos pais. Também notaram e exigem mais atenção. Perceberam a importância de um planejamento familiar para a vida futura, pois, o mundo moderno e a sociedade exigem cada vez mais das pessoas esforço, dedicação e estudos.

Esses estudantes assimilaram o conteúdo diretamente com a sustentabilidade, destacaram e falaram muito em suas palestras sobre a importância de separar o lixo reciclável do lixo orgânico, através da forma visual. Constatou-se que eles conseguiram atrelar a sustentabilidade com a saúde, que as fraldas descartáveis utilizadas podem ser fatores de risco à saúde, pois, podem conter vermes, atrair bactérias e fungos. 
Com isso, percebe-se a importância de ampliar discussões relacionando a sexualidade com a Educação Ambiental, não somente na disciplina de Ciências e no oitavo ano, mas em todas as disciplinas e em todas as séries tanto do Ensino Fundamental quanto do Ensino Médio para que, assim, haja uma interdisciplinaridade acerca dos referidos temas, já que ambas apresentam alguns valores em comum.

A educação tem um papel fundamentação na formação do indivíduo. Portanto, quanto mais relacionarmos as disciplinas e trabalharmos em conjunto mais despertaremos o interesse dos estudantes para a sua formação cidadã e às questões pertinentes ao meio ambiente e à saúde. Por isso, deve-se unir a questão ambiental com a responsabilidade em se manter distante dos riscos de uma gravidez indesejada, principalmente quando se trata de adolescentes cuja formação física e social carecem de algum limite.

É necessário que as escolas elaborem frequentemente palestras e encontros com os adolescentes estudantes, e que mais aulas com a interdisciplinaridade se elevem o tom das discussões sérias sobre a gravidez nessa etapa da vida. Então, a escola além de contribuir para a vida saudável dos estudantes, há de colaborar também com a questão ambiental, uma vez que, como ficou demonstrado, um bebê muda tudo na vida dos pais, e o que produz como resíduo muda também o meio ambiente, uma vez que tudo utilizado para a higienização da criança acaba, de alguma forma, em lixo.

\section{Referências}

Boff, L. (2015). Sustentabilidade: O que é-O que não é. Vozes.

Borda, O. F. (1988). Aspectos teóricos da pesquisa participante: considerações sobre o significado do papel da ciência na participação popular. In: Brandão, C. R. (Org.). Pesquisa Participante. (7a ed.), Brasiliense.

Brandão, C. R. (2006). A pesquisa participante e a participação da pesquisa: Um olhar entre tempos e espaços a partir da América Latina. In: Brandão, C. R., Streck, D. R. Pesquisa participante: o saber da partilha. Aparecida: Ideias \& Letras, 21-54.

Brasil. (2005). Ministério do Meio Ambiente e Ministério da Educação. Programa Nacional de Educação Ambiental. MMA e MEC.

Brasil. (1999). Lei 9.795, de 27 de abril de 1999. Dispõe sobre a educação ambiental, institui a Política Nacional de Educação Ambiental. Diário Oficial da República Federativa do Brasil. Ministério da Educação.

Conte, J. (2019). Adolescentes que engravidam sofrem maior risco de problemas físicos, psicológicos e sociais. <https://drauziovarella.uol.com.br/reportagens/adolescentes-que-engravidam-sofrem-maior-risco-de-problemas-fisicos-psicologicos-e-sociais/>.

Delboni, C. (2017). Amamentação: as 5 maiores dificuldades das mães (e como resolvê-las). <https://revistacrescer.globo.com/Bebes/Amamentacao/noticia/2017/08/amamentacao-5-maiores-dificuldades-das-maes-e-como-resolve-las.html>.

Equipe ecycle. (2019). Fraldas descartáveis: conheça perigos, impactos e alternativas. <https://www.ecycle.com.br/3831-fraldas-descartaveis-impactosalternativas>.

G1 - Globo. (2019). Lixo doméstico, problema global. <https://g1.globo.com/sc/santa-catarina/especial-publicitario/falando-desustentabilidade/noticia/2019/01/07/lixo-domestico-problema-global.ghtml

Garcia, D. (2014). O que é obsolescência programada? Brasil. < https://super.abril.com.br/mundo-estranho/o-que-e-obsolescencia-programada/ >. Acesso em 04 de março de 2021.

Higgs, J. \& Cherry, N. (2009). Doing qualitative research on practice. In: Higgs, J, Horsfall, D, Grace, S. (Eds.). Writing Qualitative Research on Practice. Rotterdam (NE): Sense Publishers, p. 3-12.

Leff, E. (2001). Saber ambiental: Sustentabilidade, Racionalidade, Complexidade, Poder. (4a ed.), Vozes/PNUMA.

Ludke, M. \& André, M. E. D. A. (2015). Pesquisa em educação: abordagens qualitativas. E.P.U.

Marques, R., Gonzalez, C. E. F., \& Xavier, C. R. (2017). As dificuldades da inserção e da prática em Educação Ambiental no currículo escolar. Anais do XVI Encontro Paranaense de Educação Ambiental. UFPR. <http://www.epea2017.ufpr.br/wp-content/uploads/2017/05/140-E4-S13-AS-DIFICULDADES-DAINSER\%C $3 \% 87 \% \mathrm{C} 3 \% 83 \mathrm{O}-1 . \mathrm{pdf}>$

Marques, R. et. al. (2017). Compostagem como ferramenta de aprendizagem para promover a Educação Ambiental no ensino de ciências. In: Forum Internacional de Resíduos Sólidos-Anais. <http://institutoventuri.org.br/ojs/index.php/firs/article/view/348 >.

Marques, R. \& Xavier, C. R. (2018). Responsabilidade socioambiental a partir da utilização e descarte de medicamentos. Revista Brasileira De Educação Ambiental (RevBEA), 13(4), 174-189. < https://doi.org/10.34024/revbea.2018.v13.2535>.

Onubr. (2018). Taxa de gravidez adolescente no Brasil está acima da média latino-americana e caribenha. <https://nacoesunidas.org/taxa-de-gravidezadolescente...//>. 
Research, Society and Development, v. 10, n. 4, e37510414353, 2021

(CC BY 4.0) | ISSN 2525-3409 | DOI: http://dx.doi.org/10.33448/rsd-v10i4.14353

Organização mundial de saúde - OMS. (2006). Defining sexual health: report of a Technical Consultation on sexual health, Genebra, 28-31 Genebra: Organização Mundial de Saúde.

Pampers. (2019). Quantas fraldas de cada tamanho o bebê vai usar. <https://is.gd/MdfTQR>.

Portal ecycle. (2019). Fast fashion e o consumismo de roupas. <https://www.ecycle.com.br/component/content/article/73-vestuario/4107-qfast-fashionq-e-oconsumismo-de-roupas.html>.

Portal são francisco. (2015) Decomposição do lixo. 〈https://www.portalsaofrancisco.com.br/meio-ambiente/decomposicao-do-lixo〉.

Reghin, M. (2017). Reciclagem de fraldas já existe no Brasil. <https://revistacrescer.globo.com/Voce-precisa-saber/noticia/2017/11/reciclagem-de-fraldas-elaja-existe-no-brasil.html>. 